\title{
Regulation of Pl-3-kinase and Akt signaling in T lymphocytes and other cells byTNFR family molecules
}

\author{
Takanori So ${ }^{1}{ }^{*}$ and Michael Croft ${ }^{2}$ * \\ 1 Department of Microbiology and Immunology, Tohoku University Graduate School of Medicine, Sendai, Japan \\ ${ }^{2}$ Division of Immune Regulation, La Jolla Institute for Allergy and Immunology, La Jolla, CA, USA
}

\section{Edited by:}

Karsten Sauer, The Scripps Research Institute, USA

\section{Reviewed by:}

Nick Gascoigne, Scripps Research Institute, USA

Robert Rickert, Sanford-Burnham Medical Research Institute, USA

Nikolai Petrovsky, Flinders Medical Centre, Australia

\section{*Correspondence:}

Takanori So, Department of Microbiology and Immunology, Tohoku University Graduate School of Medicine, 2-1 Seiryo-machi, Aobaku, Sendai 980-8578, Japan

e-mail: tso@med.tohoku.ac.jp; Michael Croft, Division of Immune Regulation, La Jolla Institute for Allergy and Immunology, 9420 Athena Circle, La Jolla, CA 92037, USA

e-mail: mick@liai.org
Activation of phosphoinositide 3-kinase ( $\mathrm{PI} 3 \mathrm{~K}$ ) and Akt (protein kinase $\mathrm{B}$ ) is a common response triggered by a range of membrane-bound receptors on many cell types. In T lymphocytes, the PI3K-Akt pathway promotes clonal expansion, differentiation, and survival of effector cells and suppresses the generation of regulatory T cells. PI3K activation is tightly controlled by signals through the T cell receptor (TCR) and the co-stimulatory receptor CD28, however sustained and periodic signals from additional co-receptors are now being recognized as critical contributors to the activation of this pathway. Accumulating evidence suggests that many members of the Tumor Necrosis Factor receptor (TNFR) superfamily, TNFR2 (TNFRSF1B), OX40 (TNFRSF4), 4-1BB (TNFRSF9), HVEM (TNFRSF14), and DR3 (TNFRSF25), that are constitutive or inducible on T cells, can directly or indirectly promote activity in the PI3K-Akt pathway. We discuss recent data which suggests that ligation of one TNFR family molecule organizes a signalosome, via TNFR-associated factor (TRAF) adapter proteins in T cell membrane lipid microdomains, that results in the subsequent accumulation of highly concentrated depots of PI3K and Akt in close proximity to TCR signaling units. We propose this may be a generalizable mechanism applicable to other TNFR family molecules that will result in a quantitative contribution of these signalosomes to enhancing and sustaining PI3K and Akt activation triggered by the TCR. We also review data that other TNFR molecules, such as CD40 (TNFRSF5), RANK (TNFRSF11A), FN14 (TNFRSF12A), TACI (TNFRSF13B), BAFFR (TNFRSF13C), and NGFR (TNFRSF16), contribute to the activation of this pathway in diverse cell types through a similar ability to recruit PI3K or Akt into their signaling complexes.

\section{Keywords: PI3K, AKT, TNFSF, TNFRSF, TRAF, signalosome}

\section{INTRODUCTION}

The response of Tlymphocytes to extrinsic stimuli has been known for many years to involve activation of phosphoinositide 3-kinase $(\mathrm{PI} 3 \mathrm{~K})$ that results in a sustained rise in the lipid second messenger phosphatidylinositol $(3,4,5)$-trisphosphate $\left(\mathrm{PIP}_{3}\right.$ or $\left.\mathrm{PI}(3,4,5) \mathrm{P}_{3}\right)$, produced from phosphatidylinositol $(4,5)$-bisphosphate $\left(\mathrm{PIP}_{2}\right.$ or $\left.\mathrm{PI}(4,5) \mathrm{P}_{2}\right)$, and translocation of a subset of proteins containing pleckstrin homology $(\mathrm{PH})$ domains to the plasma membrane, such as Akt (protein kinase B) and phosphoinositide-dependent kinase 1 (PDK1). Akt activity is regulated by the binding of $\mathrm{PIP}_{3}$ or phosphatidylinositol $(3,4)$-bisphosphate $\left(\mathrm{PI}(3,4) \mathrm{P}_{2}\right)$ to its $\mathrm{PH}$ domain, and by phosphorylation on threonine 308 by PDK1 and on serine 473 by the mammalian target of rapamycin complex 2 (mTORC2). Although PDK1 and mTORC2 may be central to Akt function, they likely have activities unrelated to Akt. For example, PDK1 also phosphorylates and activates other AGC protein kinases without binding to $\mathrm{PIP}_{3}$, such as $70 \mathrm{kDa}$ ribosomal protein S6 kinases (S6Ks), $90 \mathrm{kDa}$ ribosomal protein S6 kinases (RSKs), serum/glucocorticoid-regulated kinases (SGKs), and protein kinase Cs (PKCs) (Finlay and Cantrell, 2011). Importantly, the signaling network regulated by $\mathrm{PI} 3 \mathrm{~K}$ and Akt plays an integral role in promoting $\mathrm{T}$ cell activation, differentiation, and survival, and also participates in suppressing the induction of Foxp3-expressing regulatory $T$ cells $\left(T_{\text {reg }}\right)$ that otherwise would limit the $T$ cell response (Fruman and Bismuth, 2009; Huang and Sauer, 2010; Josefowicz et al., 2012; Okkenhaug, 2013). Activated Akt potentially regulates many downstream molecules, directly or indirectly through phosphorylation, that contribute to maximizing the $\mathrm{T}$ cell response. These include blocking the activity of forkhead box $\mathrm{O}$ (Foxo) transcription factors such as Foxol that promote differentiation of inducible $\mathrm{T}_{\mathrm{reg}}$, suppressing the activity or expression of pro-apoptotic molecules such as Bad and Bim, antagonizing the expression of cell cycle inhibitor proteins, and promoting $\mathrm{T}$ cell functionality and survival by increasing glucose uptake and glycolysis, and through augmenting IкB Kinase and NF-кB activity.

The range of membrane receptors that participate in triggering this PI3K/Akt axis in T cells may have been underappreciated. Recognition of antigen by the T cell receptor (TCR) in the context of signaling from the co-stimulatory receptor CD28 has long been known to promote PI3K activity. CD28 is constitutively expressed on T cells, and engagement by B7 molecules (CD80 and CD86) directly recruits the p85 regulatory subunit of PI3K (p85 PI3K) through a pYMNM (phospho-Tyr-Met-Asn-Met) motif located 
in CD28's cytoplasmic tail (Pages et al., 1994). The overall signaling activity of CD28, including through the PI3K and Akt pathway, participates in the initial activation and division of $\mathrm{T}$ cells in many situations, although extensive studies have also suggested that the interaction with p85 is dispensable for many functions of CD28 in naive T cells (Fruman and Bismuth, 2009). As well as CD28 and related molecules like ICOS, many additional receptors on T cells may contribute to PI3K and Akt activity. Sustained and periodic signaling from these receptors over time is increasingly being recognized as vital for continued $\mathrm{T}$ cell differentiation and survival, further suppression of $\mathrm{T}_{\text {reg }}$ development, the generation of memory, and the reactivation of memory $\mathrm{T}$ cells. Members of the tumor necrosis factor receptor (TNFR) superfamily constitute many of these receptors (Croft, 2003, 2009; Watts, 2005; So et al., 2006). Although all of the TNFR family members discussed in this review are strong activators of NF- $\kappa \mathrm{B}$, and NF- $\kappa \mathrm{B}$ certainly plays a role in many of the functional consequences of triggering these receptors, increasing evidence suggests that their ability to also target PI3K and Akt may be integral to their function. In $\mathrm{T}$ cells, these receptors include TNFR2 (TNFRSF1B), OX40 (TNFRSF4), 4-1BB (TNFRSF9), HVEM (TNFRSF14), and DR3 (TNFRSF25), which are either constitutively expressed or induced after activation (Figure 1). There are several other TNFR molecules that control T cell function, such as CD27 (TNFRSF7), CD30 (TNFRSF8), and GITR (TNFRSF18), that have yet to be described to promote activation of PI3K or Akt, however it is highly likely that they also have the ability to target this pathway (Figure 1). This review summarizes recent findings on the potential importance of TNFR family signaling in stimulating the PI3K-Akt pathway in $\mathrm{T}$ cells as well as in other cell types, and

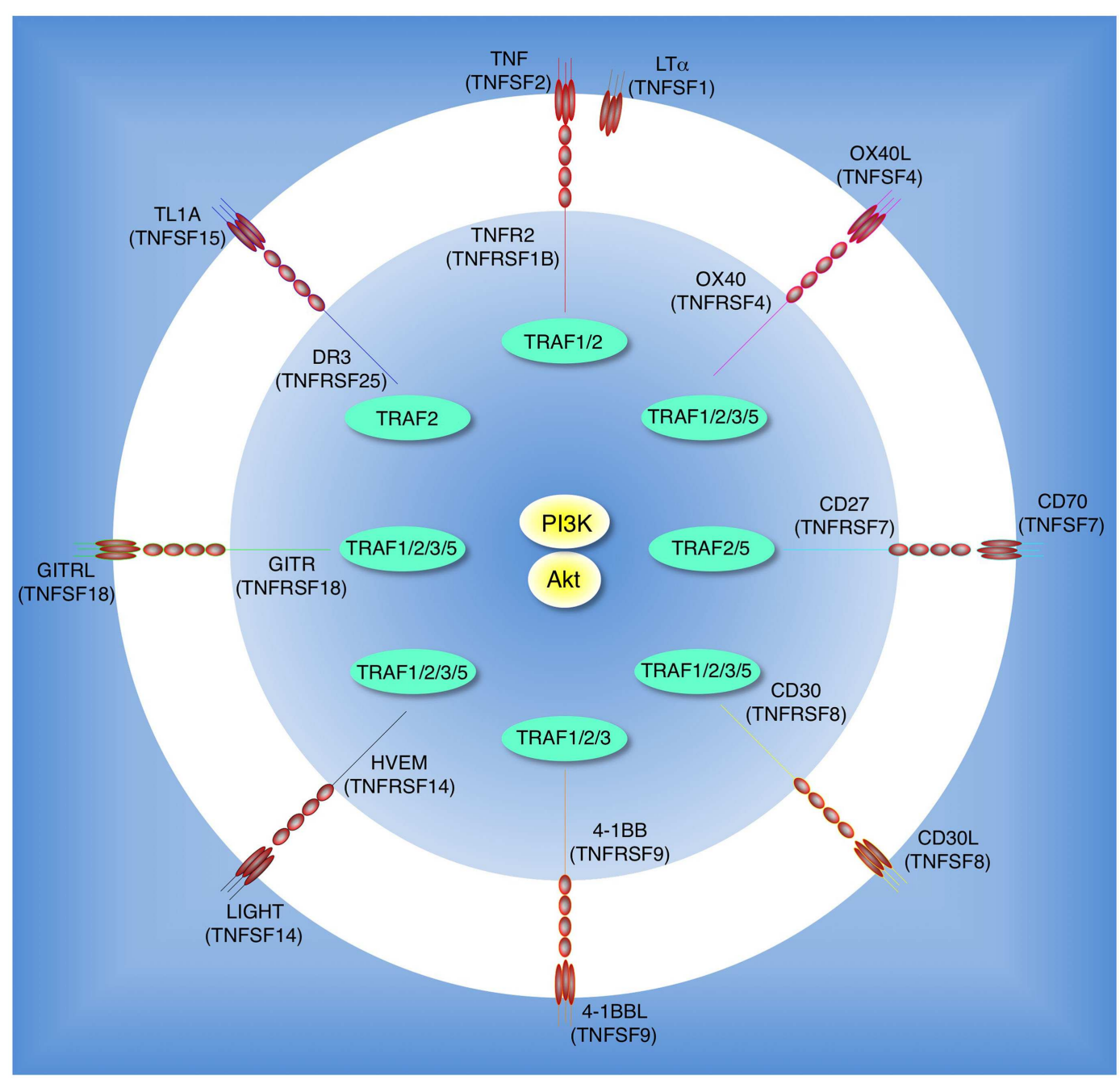

FIGURE 1 | Tumor necrosis factor receptor family molecules that possibly activate the PI3K-Akt pathway in T cells. Molecular interactions between TNF receptor superfamily (TNFRSF) members and TNF ligand superfamily (TNFSF) members: TNFR2 (TNFRSF1B) and TNF (TNFSF2) or LT $\alpha$ (TNFSF1); OX40 (TNFRSF4) and OX40L (TNFSF4); CD27 (TNFRSF7) and CD70 (TNFSF7); CD30 (TNFRSF8) and CD30L (TNFSF8); 4-1BB (TNFRSF9) and 4-1BBL
(TNFSF9); HVEM (TNFRSF14) and LIGHT (TNFSF14); GITR (TNFRSF18) and GITRL (TNFSF18); DR3 (TNFRSF25) and TL1A (TNFSF15). Interactions between TNFR-associated factors (TRAFs) and TNFRSF molecules are indicated in the inner circle. CD27, CD30, and GITR have yet to be described to promote activation of $\mathrm{PI} 3 \mathrm{~K}$ or Akt, but this is likely given their overlapping TRAF-binding capacity. 
discusses the likely mechanism of how TNFR family molecules organize signalosomes on the membrane to sustain lipid signaling. The initial sections will present a brief overview of reported activities of TNFR family members on T cells that have been described to augment PI3K or Akt activity. We will then discuss the potential molecular connections that allow these molecules to link to PI3K or Akt, and lastly review PI3K and Akt related activation by other TNFR family members in non-T cells.

\section{REGULATION OF T CELL CO-SIGNALING BY TNFRSF MEMBERS: TNFR2, 0X40, 4-1BB, HVEM, AND DR3 TNFR2 (TNFRSF1B)}

TNFR2 is mainly expressed in cells of the immune system including $\mathrm{T}$ cells. The ligand TNF (TNFSF2) is produced by activated macrophages, $\mathrm{T}$ cells, and many other cell types, and exists as a transmembrane trimer whose proteolysis also leads to a soluble form. TNFR2 is more efficiently triggered by transmembrane TNF than by soluble TNF (Grell et al., 1995; Faustman and Davis, 2010). TNFR2 is constitutively expressed on T cells and increases its expression after $\mathrm{T}$ cell activation. Interaction of TNF with TNFR2 is co-stimulatory to TCR-mediated T cell activation and effector T cell differentiation (Kim and Teh, 2001, 2004; Aspalter et al., 2003; Kim et al., 2006) and TNFR2-deficient T cells possess a defect in survival during the early phase of clonal expansion that correlates with a defect in survivin, Bcl-2, and Bcl-xL expression (Kim and Teh, 2004; Kim et al., 2006). Importantly, TNFR2 was found to sustain Akt activity in T cells stimulated through the TCR and CD28. Given the described activities of PI3K-Akt in promoting expression of the aforementioned anti-apoptotic and cell cycle related molecules in various cell types including $\mathrm{T}$ cells, this data suggested that TNFR2 triggered Akt signaling may have participated in regulating expansion and survival of these effector-type T cells (Kim and Teh, 2004). The differentiation of effector $\mathrm{T}$ cells from a naïve population is counter to the differentiation of regulatory $\mathrm{T}$ cells ( $\mathrm{iT}_{\mathrm{reg}}$ ), and activation of $\mathrm{PI} 3 \mathrm{~K}$ and Akt has been shown to block induction of Foxp3 and $\mathrm{iT}_{\text {reg }}$ development (Haxhinasto et al., 2008; Sauer et al., 2008). In line with this, neutralization of TNF has also recently been found to enhance development of $\mathrm{iT}_{\text {reg }}$ cells (Zhang et al., 2013). TGF- $\beta$-induced Smad3 phosphorylation directs transcription of Foxp3 and formation of $i \mathrm{~T}_{\text {reg }}$, and phosphorylation of Akt through TNF-TNFR2 interaction was described to facilitate Akt-Smad3 interaction and suppress Foxp3 expression, potentially explaining in part why TNF would block $\mathrm{iT}_{\text {reg }}$ differentiation (Zhang et al., 2013).

Substantiating that Akt is a general target of TNF signaling, Akt phosphorylation has also been shown to be enhanced through TNFR1 and/or TNFR2 in various cell types, such as HEK293 cells (Ozes et al., 1999), HeLa cells (Ozes et al., 1999; Pastorino et al., 1999), HepG2 cells (Reddy et al., 2000), U937 cells (Reddy et al., 2000), endothelial cells (Zhang et al., 2003a), fibroblasts (Hanna et al., 1999; Zhang et al., 2001), myocytes (Hiraoka et al., 2001), cortical neurons (Marchetti et al., 2004), and hepatocytes (Osawa et al., 2001).

\section{OX40 (TNFRSF4)}

OX40 is induced on activated T cells while its ligand, OX40L (TNFSF4), is inducible on professional antigen-presenting cells
(APCs). OX40-OX40L interactions positively regulate conventional $\mathrm{T}$ cell responses and can negatively affect $\mathrm{T}_{\text {reg }}$ differentiation (So et al., 2008; Croft et al., 2009; Croft, 2010; Ishii et al., 2010). OX40 functions later than CD28, and potentially later than TNFR2, providing signals to promote continued division and survival, and hence clonal expansion of effector and memory $\mathrm{T}$ cells (Gramaglia et al., 2000). OX40 signaling was shown to augment and sustain PI3K-Akt activity when antigen was presented to $\mathrm{T}$ cells, again correlating with its ability to promote continued expression of molecules that control cell cycle progression as well as anti-apoptotic Bcl-2 family members (Rogers et al., 2001; Song et al., 2004, 2005). Importantly, a dominant-negative version of Akt reproduced many of the defects associated with a lack of OX40 expression, and introduction of a constitutively active version of Akt into $\mathrm{T}$ cells that lacked OX40 almost fully reversed the defect in clonal expansion and survival exhibited by these $\mathrm{T}$ cells (Rogers et al., 2001; Song et al., 2004, 2005). OX40 signaling also antagonizes the differentiation of Foxp3+ or IL-10+ $\mathrm{iT}_{\text {reg }}$ (Ito et al., 2006; So and Croft, 2007; Vu et al., 2007). No formal proof has been provided that OX40 inhibition of Foxp3 and $\mathrm{iT}_{\text {reg }}$ development is mediated in part by Akt activation, but again this is likely.

\section{4-1BB (TNFRSF9)}

$4-1 \mathrm{BB}$ is another inducible molecule on activated $\mathrm{T}$ cells that can be triggered by 4-1BBL (TNFSF9) expressed on activated APCs (So et al., 2008; Snell et al., 2011; Vinay and Kwon, 2012). 4-1BB ligation can again promote $\mathrm{T}$ cell clonal expansion, differentiation, and expression of cytokines, and can enhance the survival of effector and memory $\mathrm{T}$ cells through upregulation of $\mathrm{Bcl}-\mathrm{XL} \cdot 4-1 \mathrm{BB}$ signaling also has the ability to inhibit TGF- $\beta$-driven conversion of naïve $\mathrm{CD}^{+}{ }^{+} \mathrm{T}$ cells into $\mathrm{iT}_{\text {reg }}$ either through direct activity or indirectly via upregulation of IFN $\gamma$ production (Madireddi et al., 2012). 4-1BB was found to promote phosphorylation of Akt in T cells, and proliferative responses mediated by $4-1 \mathrm{BB}$ were blocked by a PI3K inhibitor, coincident with suppressing cyclin expression and promoting the cell cycle regulatory molecules $\mathrm{p} 27^{\mathrm{kip} 1}$ (Lee et al., 2002, 2003). Some studies suggested that 4-1BB induced the anti-apoptotic Bcl-2 family molecules, Bcl-2 and Bcl-xL, in murine $\mathrm{T}$ cells in a PI3K-Akt independent manner (Lee et al., 2002 , 2003). However, suppression of apoptosis and induction of

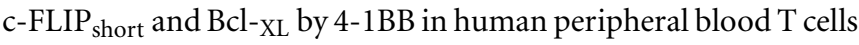
was blocked by targeting PI3K or Akt (Starck et al., 2005).

\section{HVEM (TNFRSF14)}

HVEM can interact with a number of different ligands, however its primary activating ligand in the TNF family is LIGHT (TNFSF14). HVEM is widely expressed on many cell types, including being constitutive on T cells. LIGHT in contrast is inducible on T cells as well as certain APCs such as DC and B cells upon activation (Steinberg et al., 2011; Ware and Sedy, 2011). Ligation of HVEM by LIGHT provides stimulatory signals that additionally can impact activation, differentiation, or survival of T cells. In line with HVEM controlling Akt activation at later stages of T cell responses, HVEM-deficient T cells were shown to display reduced Akt activity at the peak of the effector response that correlated with defective expression of $\mathrm{Bcl}-2$ and reduced $\mathrm{T}$ cell survival. 
Furthermore, the defect in T cell survival was rescued by ectopic expression of an active form of Akt (Soroosh et al., 2011).

Substantiating Akt as a downstream target of HVEM, the ability of LIGHT to induce macrophage migration and vascular smooth muscle cell proliferation also correlated with activation of PI3K and Akt (Wei et al., 2006), and LIGHT was found to promote PI3K-Akt phosphorylation in osteoclast precursor cells, supporting osteoclast differentiation (Hemingway et al., 2013).

\section{DR3 (TNFRSF25)}

DR3 is constitutively expressed by T cells and is upregulated following T cell activation, while TL1A (TNFSF15), the ligand for DR3, is induced in APCs (Meylan et al., 2011). Interaction of TL1A with DR3 also provides costimulatory signals to T cells in concert with antigen/TCR signaling and this can contribute to enhanced production of pro-inflammatory cytokines, and increased clonal expansion and differentiation of T cells. Although no studies have been conducted as yet on conventional T cells, ligation of DR3 was shown to promote $\mathrm{T}_{\text {reg }}$ proliferation that was blocked by an Akt inhibitor (Schreiber et al., 2010). Stimulation of DR3-expressing human acute monocytic leukemia THP-1 cells with TL1A, or antiDR3 antibodies, also induced phosphorylation of Akt concomitant with upregulation of expression of $\beta$ ig-h3, an extracellular matrix protein. This was blocked by an inhibitor of PI3K and inhibitors of PKC, suggesting that PKC activation by DR3 may be involved in PI3K-Akt activation via this receptor in this cell type (Lee et al., 2010). Lastly, E-selectin (CD62E) has been suggested to be an alternate ligand for DR3, and E-selectin was found to activate the PI3K-Akt pathway via DR3 in HT29 colon carcinoma cells (Porquet et al., 2011).

\section{TNF RECEPTOR OLIGOMERIZATION, MEMBRANE LIPID MICRODOMAINS, AND THE T CELL TNFR SIGNALOSOME}

Although the studies described above show that TNFR2, OX40, 4-1BB, HVEM, and DR3 can enhance PI3K and Akt activation in $\mathrm{T}$ cells or other cell types, a primary question is whether this is a direct activity, or indirect through modulating or enhancing signaling through other non-TNFR molecules including the TCR or CD28. Moreover, as these TNFR molecules do not have obvious PI3K-binding motifs, similar to the pYMNM motif of CD28, it is not clear how they would directly link to $\mathrm{PI} 3 \mathrm{~K}$ or Akt or how the connection with the lipid mediators is facilitated.

TNF family ligands share the TNF homology domain (THD), which binds to cysteine-rich domains (CRDs) of the TNF family receptors. TNF ligands are synthesized as either membrane-bound or soluble trimeric proteins. Many biochemical and functional studies show that the transmembrane ligands can robustly activate receptors whereas the soluble trimeric ligands differ in their ability to be activating molecules. Some TNFR molecules, such as TNFR1 and CD40, are thought to be pre-clustered at the cell surface in the absence of their cognate TNF ligand (Chan, 2007), which likely aids their ability to respond to the soluble ligand. This is exemplified by TNF, which is highly active in soluble form when recognizing TNFR1. In contrast, studies of trimers of molecules such as OX40L and 4-1BBL have suggested they do not have functional effects when soluble, implying their receptors are not pre-assembled into clusters. However, artificially generated oligomerized versions of soluble trimeric ligands, including OX40L, 4-1BBL, and GITRL work as highly efficient agonists in T cells and other cell types (Haswell et al., 2001; Zhang, 2004; Stone et al., 2006; Muller et al., 2008; Zhou et al., 2008; Wyzgol et al., 2009). Other variants on this theme are molecules like APRIL whose soluble form can be oligomerized naturally through interaction with polysaccharide side chains of heparin sulfate proteoglycans, allowing effective signals through its receptors TACI or BCMA (Ingold et al., 2005; Kimberley et al., 2009); or BAFF that also binds to TACI, and is unable to activate this receptor as a single trimer, but can assemble as an ordered structure comprising 20 trimers (60-mer) and then gains the ability to be a strong TACI agonist (Liu et al., 2002; Bossen et al., 2008). In sum, these results suggest that oligomerization of most TNFR molecules, beyond the basic trimer complex that would be formed after ligation of a single trimeric ligand, is a prerequisite for efficient recruitment and activation of signaling moieties.

All TNFR family molecules also promote intracellular kinase activation at least in part through adaptor proteins called TNFRassociated factors (TRAFs). For example, TNFR2 has the potential ability to recruit and/or directly bind TRAFs 1 and 2 (Rothe et al., 1994); OX40: TRAFs 1, 2, 3, and 5 (Kawamata et al., 1998); 41BB: TRAFs 1, 2, and 3 (Jang et al., 1998); HVEM: TRAFs 1, 2, 3, and 5 (Marsters et al., 1997); and DR3: TRAF2 (Chinnaiyan et al., 1996). TRAF proteins already can exist as trimers in the cytosol before binding to the cytoplasmic tails of TNF receptors (Park et al., 1999), suggesting that oligomerization of the receptors will then additionally result in oligomerized scaffolds of at least one, but more likely multiple, TRAF molecules.

Another facet that might be important to the ability of TNFR family molecules to link to PI3K and Akt directly is the regulated movement of TNFR oligomers into detergentinsoluble cholesterol- and sphingolipid-rich plasma membrane microdomains (DIM or lipid rafts). Here the spatiotemporal regulation of protein-protein interactions and dynamic protein networks may orchestrate to allow any biological outcome (Dykstra et al., 2003; Viola and Gupta, 2007). DIM are estimated as $<20 \mathrm{~nm}$ diameter in a living cell (Eggeling et al., 2009), indicating that molecules that translocate into DIM are likely condensed into a small area. Although not investigated for many TNFR molecules to date, particularly in $\mathrm{T}$ cells, several members of the family have been visualized to concentrate in DIM after stimulation by their ligands including OX40 (So et al., 2011a,b) and 4-1BB (Nam et al., 2005). Therefore, translocation into lipidrich microdomains might be a common and important feature of the TNFR family. Moreover, TRAF2 can interact with Filamin-A, which functions as a scaffold for DIM formation (Leonardi et al., 2000; Arron et al., 2002), and with Caveolin-1, which is a component of DIM (Feng et al., 2001), suggesting that recruitment of this molecule might promote or maintain localization of TNFR molecules in these lipid-rich areas. TRAF2 binding is shared by all TNFR family molecules that have been described to co-stimulate T cells (Figure 1), including those shown to date to promote PI3K and Akt activation (see above), implying TRAF2 may be a critical link to PI3K and/or Akt. Perhaps of equal significance, $\mathrm{PIP}_{2}$ is enriched and constitutively associated with DIM, and at least 
in T cells, a proportion of total cellular PI3K and PDK1 are constitutively associated with detergent-insoluble fractions (Pike and Casey, 1996; Dykstra et al., 2003; So et al., 2011a). Therefore, it is reasonable to suggest that these lipid-rich microdomains are likely to play a critical role in triggering PI3K-Akt signaling by facilitating the localization of oligomerized TNFR and TRAF molecules with PI3K, PIP 2 , and PDK1 (Lasserre et al., 2008). This would enhance the likelihood of $\mathrm{PIP}_{3}$ production, and membrane recruitment and phosphorylation of Akt, assuming PI3K can be activated.

Only studies of one molecule to date have shown a direct link of a TNFR family molecule to PI3K and Akt in T cells. However, there is strong rationale that the findings will be generalizable. We clearly demonstrated in several studies that OX40 signaling strongly synergizes with antigen signals to augment Akt activity in recently activated or effector T cells (Song et al., 2004; So et al., 2011a,b). After interaction of OX40 with transmembrane OX40L, OX40 moved into DIM and immunoprecipitation experiments revealed that it organized a signalosome containing many molecules including TRAF2, the IKK complex, and PKC $\theta$ and the CARMA1-BCL10-MALT1 complex, that regulate NF- $\kappa \mathrm{B} 1$ activation, and also including p85 PI3K and Akt (So et al., 2011a,b). The formation of this complete OX40 signalosome in T cells was dependent on TRAF2 and on translocation of OX40 into DIM, but independent of antigen/TCR stimulation (So et al., 2011a,b). Moreover, in the absence of TRAF2 or by disrupting DIM, OX40 could not complex with either PI3K or Akt. Interestingly, OX40 was unable to induce significant cellular phosphorylation of PI3K, $\mathrm{PIP}_{3}$ accumulation, or Akt activation, unless antigen was presented to the T cells, even though antigen/TCR signaling had no obvious impact on recruitment of PI3K or Akt to the OX40 signalosome. The explanation for this was not clear, but we only found a moderate amount of PDK1 associated with the OX40 complex suggesting that this might in part contribute to the inability of OX40 ligation in isolation to lead to phosphorylation of Akt, and why antigen recognition was essential. However, more recent data have shown that OX40 associates with an E3 ligase that appears to limit its ability to activate Akt in T cells (Croft, unpublished). This then suggests that OX40 does possess the capacity to activate Akt independently of other receptors, but regulatory elements may keep this ability in check in T cells providing control over this aspect of OX40 biology to the TCR. Importantly, these data then imply that OX40 functions in $\mathrm{T}$ cells by quantitatively enhancing the amount of PI3K and Akt that is available to be activated in the lipid-rich microdomain environment. We hypothesize that the higher ordered oligomerized TNFR-ligand modules that are organized in DIM of T cells essentially offer functional hot spots of concentrated PI3K and Akt in the vicinity of the TCR/CD28 signalosome (Figure 2). These data also highlight that TRAF adaptors are likely to play critical roles in linking the TNFR family to PI3K and Akt in T cells. Our studies show that TRAF2 is important for OX40 to recruit both PI3K and Akt into its signaling complex, but whether TRAF2 directly binds one or both molecules is not yet clear. Other TRAFs, particularly TRAF6, may be also critical as described below in non-T cells, although how much this might vary from a $\mathrm{T}$ cell to another cell type is also not clear.

\section{REGULATION OF PI3K AND AKT BY TNFRSF MEMBERS IN NON-T CELLS: CD40, RANK, FN14, TACI/BAFFR, AND NGFR CD40 (TNFRSF5)}

Signaling through CD40 after ligation by CD40L (TNFSF5) is important for promoting the activation, division, and maturation of APCs, and isotype switching of B cells (Graham et al., 2010; Gommerman and Summers deLuca, 2011). CD40 can directly bind to TRAFs 1, 2, 3, 5, and 6 (Pullen et al., 1998) and CD40 engagement leads minimally to translocation of CD40, TRAF2, TRAF3, and TRAF6 into DIM where CD40 activates downstream signaling cascades (Hostager et al., 2000; Vidalain et al., 2000; Arron et al., 2001). Cross-linking CD40 has been found to activate PI3K in the Daudi human B lymphoblastoid line (Ren et al., 1994), and promote Akt phosphorylation, downregulation of $\mathrm{p} 27^{\mathrm{kip} 1}$, and upregulation of $\mathrm{Bcl}-\mathrm{XL}$, in primary murine $\mathrm{B}$ cells that was blocked by a PI3K inhibitor (Andjelic et al., 2000). CD40-induced proliferation and survival of B cells deficient in a negative regulatory adaptor molecule was also suppressed by introduction of dominant-negative Akt (Aiba et al., 2006). After triggering CD40 on murine bone marrow-derived DCs, p85 PI3K was furthermore found to be recruited to CD40 correlating with enhanced Akt activation (Arron et al., 2001). Similarly, CD40L induced Akt phosphorylation and survival in human monocytederived DCs that was blocked with a PI3K inhibitor (Yu et al., 2004). In other cells, stimulation of CD40 on human microvascular endothelial cells also induced PI3K and Akt phosphorylation, concomitant with an increase in cell survival and proliferation, and these functional activities were suppressed by PI3K inhibitors and a dominant-negative version of Akt (Deregibus et al., 2003).

Although the adaptors required for CD40 to connect to PI3K and Akt have not been investigated in every situation, several pieces of evidence suggest TRAF6 and/or TRAF2 are crucial. For example, CD40 was shown to block apoptosis induced by the Fas death receptor in a PI3K and Akt dependent manner, and this was abrogated in B cells that were deficient in TRAF6 (Benson et al., 2006). A CD40 signalosome containing TRAF2, TRAF6, and p85 PI3K was also visualized in endothelial cells (Deregibus et al., 2003) and a signalosome of TRAF6 and PI3K in DCs (Arron et al., 2001). Lastly, fibroblasts lacking TRAF2 or TRAF6 displayed impaired Akt phosphorylation that was triggered by CD40 engagement (Davies et al., 2005).

\section{RANK (TNFRSF11A)}

RANK interactions with RANKL (TNFSF11) regulate bone remodeling, lymph node formation, establishment of the thymic microenvironment, and mammary gland development during pregnancy (Leibbrandt and Penninger, 2008). RANK has the potential to recruit TRAFs 1, 2, 3, 5, and 6 (Wong et al., 1998; Darnay et al., 1999) and triggering of RANK with RANKL has been shown to promote activation of the PI3K-Akt pathway in osteoclasts and DCs. Similar to CD40, RANK was visualized to induce a signalosome containing TRAF6 and p85 PI3K in these cell types. PP1, an inhibitor for Src family kinases, inhibited Akt phosphorylation mediated by RANK, indicting that $\mathrm{c}-\mathrm{Src}$ is an upstream regulator of PI3K. In accordance, the kinase activity of c-Src was upregulated in the RANK signalosome and RANK was 


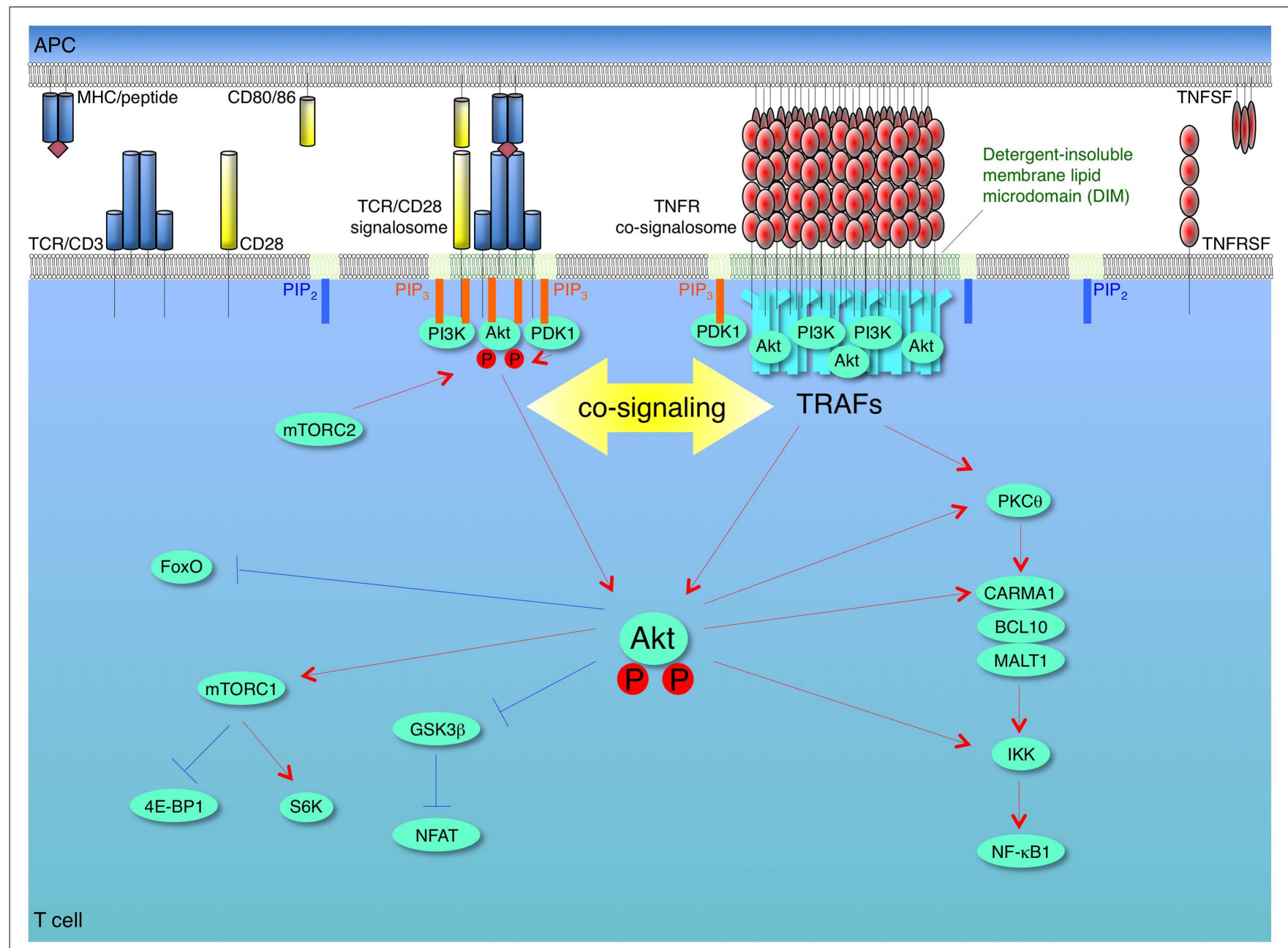

\section{FIGURE 2 | Model of synergy between TCR/CD28 and TNFR} signalosomes for activation of the PI3K-Akt pathway in T cells. T cells are activated firstly by recognition of antigen by the T cell receptor (TCR)/CD3 complex when it is displayed by the major histocompatibility complex (MHC) on antigen-presenting cells (APCs). The second co-stimulatory signal is delivered through CD28 by interaction with its ligands CD80 and/or CD86. These combined signals can activate phosphoinositide 3-kinase (PI3K), which leads to conversion of $\mathrm{PIP}_{2}$ into $\mathrm{PIP}_{3}$ at the plasma membrane. The pleckstrin homology $(\mathrm{PH})$ domain containing proteins, Akt (protein kinase $\mathrm{B}$ ) and phosphoinositide-dependent kinase 1 (PDK1), are recruited to the membrane $\mathrm{PIP}_{3}$, and then Akt is phosphorylated by PDK1 and by the mammalian target of rapamycin complex 2 (mTORC2). This promotes translocation of Akt from membrane to cytosol, thereby allowing regulation of downstream pathways through phosphorylation of target molecules, such as glycogen synthase kinase $3 \beta$ (GSK3 $\beta$ ), forkhead box O (Foxo), and IKB kinase (IKK). Akt phosphorylates and inactivates two negative regulators of $\mathrm{mTORC1}$, tuberous sclerosis complex 2 (TSC2) and proline-rich Akt substrate of $40 \mathrm{kDa}$ (PRAS40), which results in activation of mTORC1. Akt contributes to NF-KB activation through phosphorylation of IKK and interaction with protein kinase $\mathrm{C} \theta(\mathrm{PKC} \theta)$ or caspase-recruitment domain (CARD)-membrane-associated guanylate kinase (MAGUK) protein 1 (CARMA1). After recognition of trimeric TNF ligand superfamily (TNFSF) molecules on APCs, TNF receptor superfamily (TNFRSF) molecules on T cells are trimerized and oligomerized and recruit trimeric TNFR-associated factors (TRAFs) to their cytoplasmic TRAF-binding motifs. The TNFSF-TNFRSF complex then translocates into detergent-insoluble membrane lipid microdomains (DIM). The TNFRSF-TRAF superclusters recruit and allow the efficient accumulation of PI3K and Akt in concentrated depots in close proximity to the TCR/CD28 signalosome, which results in a quantitative contribution of TNFR signalosomes to enhancing and sustaining PI3K and Akt activation triggered by the TCR/CD28 signalosome. The TNFR signalosomes also can promote activation of NF-KB irrespective of TCR/CD28 signaling. Red lines show activating signals, blue lines show inhibitory signals. found unable to activate Akt without the enzymatic activity of c-Src (Wong et al., 1999; Arron et al., 2001; Xing et al., 2001).

TRAF6 again may be critical for the ability of RANK to target the PI3K-Akt pathway, and certain elements might also limit Akt activation. Upon stimulation of RANK in the RAW264.7 monocyte/macrophage cell line, phosphorylation of PI3K and Akt was upregulated and this was further amplified by introduction of dominant-negative SHP-1. TRAF6 was found to interact with RANK and SHP-1, and SHP-1 antagonized the association between RANK and TRAF6 (Zhang et al., 2003b). Similar to other TNFR molecules, RANK may also function in the context of DIM. After engagement by RANKL in osteoclasts, TRAF6 was shown to translocate into DIM where c-Src is constitutively resident, and disruption of DIM reduced Akt activation and concomitantly blocked osteoclast differentiation, survival, and bone resorption activity (Ha et al., 2003). 


\section{FN14 (TNFRSF12A)}

FN14 is another TNFR molecule. It is expressed on epithelial cells, endothelial cells, and other non-hematopoietic cells and engages TWEAK (TNFSF12) and promotes a number of differentiation activities depending on the cell type. Stimulation of FN14 on mouse osteoblastic MC3T3-E1 cells induced Akt phosphorylation and RANTES production in a PI3K-dependent manner (Ando et al., 2006). TWEAK also promoted expression of ICAM-1 and VCAM-1 on human gingival fibroblasts that was blocked with an inhibitor of PI3K (Hosokawa et al., 2006), and Akt phosphorylation and matrix metalloprotease-9 (MMP-9) expression in mouse C2C12 myotubes was suppressed by targeting PI3K or introducing a dominant-negative version of Akt (Kumar et al., 2009). Similar results were also reported with TWEAK activation of FN14 on: renal tubular epithelium cells where PI3K inhibitors prevented upregulation of cyclin D1 and cell proliferation (Sanz et al., 2009); cardiomyocytes where FN14-mediated proliferation was also blocked by interfering with PI3K activity (Novoyatleva et al., 2010); and human gingival fibroblasts where the PI3K-Akt pathway contributed to induction of CCL20 (Hosokawa et al., 2012). FN14 has the potential to directly recruit and bind TRAFs 1, 2, 3, and 5 (Brown et al., 2003) but no studies to date have attempted to link a specific TRAF to the ability of FN14 to phosphorylate and activate PI3K or Akt.

\section{TACI (TNFRSF13B)/BAFFR (TNFRSF13C)/BCMA (TNFRSF17)}

TACI, BAFFR, and BCMA are mainly expressed on B cells and play critical roles in survival of B cells at distinct stages of development by engaging APRIL (TNFSF13) and/or BAFF (TNFSF13B) (Rickert et al., 2011). BAFFR can activate the PI3K-Akt pathway in mature B cells (Patke et al., 2006; Otipoby et al., 2008; Woodland et al., 2008) and BAFF-mediated proliferative and survival responses were defective in B cells lacking p110 $\mathrm{PI} 3 \mathrm{~K}$ (Henley et al., 2008). PKC $\beta$ was found to interact and directly phosphorylate Akt on serine 473 after ligation of BAFFR, with Akt phosphorylation being greatly reduced in PKC $\beta$-deficient $B$ cells (Patke et al., 2006). Follicular lymphoma B cells were additionally found to respond to APRIL-TACI stimulation by phosphorylating p85 PI3K, Akt, mTOR, 4E-BP1, and p70S6K, and PI3K inhibitors blocked these APRIL-induced activities and cellular proliferation (Gupta et al., 2009).

Stimulation of human myeloma cells expressing TACI, BAFFR, and BCMA with BAFF or APRIL has also been shown to activate the PI3K-Akt pathway concomitant with protection against apoptosis (Moreaux et al., 2004); and lastly human adiposederived stem cells additionally phosphorylated Akt after exposure to APRIL or BAFF (Zonca et al., 2012). Similar to other TNFR family members, TACI, BAFFR, and BCMA may directly recruit and bind TRAFs 2, 5, and 6 (Xia et al., 2000), TRAFs 2 and 3 (Xu and Shu, 2002), and TRAFs 1, 2, 3, 5, and 6 (Hatzoglou et al., 2000; Shu and Johnson, 2000), respectively, suggesting that TRAF2 and/or 6 may again mediate PI3K-Akt signaling, although no studies have addressed this as yet.

\section{NGFR (TNFRSF16, p75 ${ }^{\text {NTR }}$ )}

Lastly, NGFR that is mainly expressed on neurons and glia during development of the central nervous system, and is induced after many types of nervous system injury, also appears to utilize PI3K and Akt for certain activities. NGFR only binds neurotrophins [nerve growth factor (NGF); brain-derived neurotrophic factor (BNDF); and neurotrophin-3 and -4 (NT-3 and -4)]. NGFR may primarily work as a co-receptor and cooperates with the Trk receptor tyrosine kinase family (Trk-A, -B, and -C), Sortilin-family receptors, and Nogo receptor/Lingo-1 (Ibanez and Simi, 2012). Many studies (e.g., refs Soltoff et al., 1992; Yao and Cooper, 1995; Jackson et al., 1996; Vaillant et al., 1999; Takano et al., 2000) have shown that NGF activates $\mathrm{PI} 3 \mathrm{~K}$ and induces $\mathrm{PIP}_{3}$ production, and that the Akt pathway works as a key regulator of neurotrophininduced neuronal survival. NGFR signaling is initiated in caveolae, which are a special type of DIM and serve as signaling platforms (Bilderback et al., 1999; Huang et al., 1999), but the contribution of individual TRAF molecules to activation of PI3K and Akt has not yet been reported. NGFR can directly bind TRAFs 2 and 6 (Khursigara et al., 1999; Ye et al., 1999), and TRAF6 recruitment has been suggested to be essential for signal transduction activity (Vilar et al., 2009), again implying this receptor may connect to the PI3K-Akt pathway via similar TRAF adaptors as other members of the TNFR family.

\section{CONCLUSION}

In conclusion, many stimulatory TNFR family members have been reported to augment PI3K and Akt activation in diverse cell types, suggesting that this pathway can be a major contributor to the functional effects mediated by these molecules. After interaction with their transmembrane, and in some cases soluble, TNF family ligands, TNFR molecules oligomerize and organize signalosomes in membrane lipid microdomains. The cytoplasmic domain of TNFR family members does not have the consensus motif that can directly bind PI3K. Rather, TNFR molecules bind to overlapping but distinct subsets of TRAF adaptor proteins, and these adaptors initiate many of the signals delivered by the receptors. Increasing evidence suggests that TRAF2 and/or TRAF6 are required for recruitment of PI3K or Akt into TNFR signalosomes, but whether these TRAF molecules directly bind to $\mathrm{PI} 3 \mathrm{~K}$ or Akt is not clear. In overexpression studies, and in MEFs stimulated with IGF-1 or IL-1, TRAF6 was precipitated with Akt, and furthermore TRAF6 induced K63-linked ubiquitination and membrane localization of Akt (Yang et al., 2009). Thus it is possible that this is also a primary activity when TRAF6 is recruited to a TNFR molecule. However, not all TNFR family members that have been reported to promote PI3K and Akt activation appear to bind or recruit TRAF6, but they may all interact with TRAF2. This implies that TRAF2 could be the crucial adaptor in some cases, but whether TRAF2 possesses the same activity as TRAF6 in being able to complex with, and ubiquitinate, Akt is presently unknown.

In T cells, TNFR family molecules are crucial for clonal expansion and survival, and for the generation of $\mathrm{T}$ cell memory, and increasing evidence suggests these functional effects are in part mediated by enhancing antigen-initiated PI3K and Akt activity. Some TNFR family molecules in non-T cells appear to have the capacity to activate PI3K and Akt without signaling from other receptors, suggesting they may directly phosphorylate PI3K and/or recruit other kinases that can perform this function, and they 
may also recruit kinases such as PDK1 that phosphorylate Akt. In contrast, most evidence suggests that in T cells the ability of TNFR molecules to promote phosphorylation of PI3K and Akt is restricted unless the TCR recognizes antigen. This makes sense as $\mathrm{T}$ cells are governed by many checkpoints that limit their response in an attempt to control autoreactivity. Thus, it is likely that the higher-order TNFR-TRAF superclusters induced within lipid-rich microdomains of $\mathrm{T}$ cells then allow the efficient accumulation of PI3K and Akt in concentrated depots in close proximity to the TCR signalosome, and the function of this would be to either

\section{REFERENCES}

Aiba, Y., Yamazaki, T., Okada, T., Gotoh, K., Sanjo, H., Ogata, M., et al. (2006). BANK negatively regulates Akt activation and subsequent $B$ cell responses. Immunity 24, 259-268. doi:10.1016/j.immuni.2006.01.002

Andjelic, S., Hsia, C., Suzuki, H., Kadowaki, T., Koyasu, S., and Liou, H. C. (2000). Phosphatidylinositol 3kinase and NF-kappa B/Rel are at the divergence of CD40-mediated proliferation and survival pathways. $J$. Immunol. 165, 3860-3867.

Ando, T., Ichikawa, J., Wako, M., Hatsushika, K., Watanabe, Y., Sakuma, M., et al. (2006). TWEAK/Fn14 interaction regulates RANTES production, BMP-2-induced differentiation, and RANKL expression in mouse osteoblastic MC3T3-E1 cells. Arthritis Res. Ther. 8, R146. doi:10.1186/ar2038

Arron, J. R., Pewzner-Jung, Y., Walsh, M. C., Kobayashi, T., and Choi, Y. (2002). Regulation of the subcellular localization of tumor necrosis factor receptor-associated factor (TRAF) 2 by TRAF1 reveals mechanisms of TRAF2 signaling. J. Exp. Med. 196, 923-934. doi:10.1084/jem.20020774

Arron, J. R., Vologodskaia, M., Wong, B. R., Naramura, M., Kim, N., Gu, H., et al. (2001). A positive regulatory role for Cbl family proteins in tumor necrosis factor-related activationinduced cytokine (trance) and CD40L-mediated Akt activation. J. Biol. Chem. 276, 30011-30017. doi:10.1074/jbc.M100414200

Aspalter, R. M., Eibl, M. M., and Wolf, H. M. (2003). Regulation of TCRmediated $\mathrm{T}$ cell activation by TNFRII. J. Leukoc. Biol. 74, 572-582. doi:10.1189/jlb.0303112

Benson, R. J., Hostager, B. S., and Bishop, G. A. (2006). Rapid CD40-mediated rescue from CD95-induced apoptosis requires TNFR-associated factor- 6 and PI3K. Eur. J. Immunol. 36, 2535-2543. doi:10.1002/eji.200535483

Bilderback, T. R., Gazula, V. R., Lisanti, M. P., and Dobrowsky, R. T. (1999). Caveolin interacts with
Trk A and p75(NTR) and regulates neurotrophin signaling pathways. J. Biol. Chem. 274, 257-263. doi:10.1074/jbc.274.1.257

Bossen, C., Cachero, T. G., Tardivel, A., Ingold, K., Willen, L., Dobles, M., et al. (2008). TACI, unlike BAFF-R, is solely activated by oligomeric BAFF and APRIL to support survival of activated B cells and plasmablasts. Blood 111, 1004-1012. doi:10.1182/blood-2007-09-11 0874

Brown, S. A., Richards, C. M., Hanscom, H. N., Feng, S. L., and Winkles, J. A. (2003). The Fn14 cytoplasmic tail binds tumour-necrosis-factorreceptor-associated factors $1,2,3$ and 5 and mediates nuclear factorkappaB activation. Biochem. J. 371, 395-403. doi:10.1042/BJ20021730

Chan, F. K. (2007). Three is better than one: pre-ligand receptor assembly in the regulation of TNF receptor signaling. Cytokine 37, 101-107. doi:10.1016/j.cyto.2007.03.005

Chinnaiyan, A. M., O’Rourke, K., Yu, G. L., Lyons, R. H., Garg, M., Duan, D. R., et al. (1996). Signal transduction by DR3, a death domain-containing receptor related to TNFR-1 and CD95. Science 274, 990-992. doi:10.1126/science.274.5289.990

Croft, M. (2003). Co-stimulatory members of the TNFR family: keys to effective T-cell immunity? Nat. Rev. Immunol. 3, 609-620. doi:10.1038/nri1148

Croft, M. (2009). The role of TNF superfamily members in T-cell function and diseases. Nat. Rev. Immunol. 9, 271-285. doi:10.1038/nri2526

Croft, M. (2010). Control of immunity by the TNFR-related molecule OX40 (CD134). Annu. Rev. Immunol. 28, 57-78. doi:10.1146/annurevimmunol-030409-101243

Croft, M., So, T., Duan, W., and Soroosh, P. (2009). The significance of OX40 and OX40L to T-cell biology and immune disease. Immunol. Rev. 229, 173-191. doi:10.1111/j.1600065X.2009.00766.X

Darnay, B. G., Ni, J., Moore, P. A., and Aggarwal, B. B. (1999). Activation

relieve a molecular checkpoint that limits Akt phosphorylation, or would be to simply provide more molecules of Akt available to the TCR. Further work in this area is required to fully understand the nature of TNFR signalosomes and how they may differ from molecule to molecule and in T cells versus other cell types.

\section{ACKNOWLEDGMENTS}

Michael Croft is supported by NIH grants CA91837, AI49453, AI089624, AI100905, and AI070535.

of NF-kappaB by RANK requires tumor necrosis factor receptorassociated factor (TRAF) 6 and NFkappaB-inducing kinase. Identification of a novel TRAF6 interaction motif. J. Biol. Chem. 274, 7724-7731. doi:10.1074/jbc.274.12.7724

Davies, C. C., Mak, T. W., Young, L. S., and Eliopoulos, A. G. (2005). TRAF6 is required for TRAF2-dependent CD40 signal transduction in nonhemopoietic cells. Mol. Cell. Biol. 25, 9806-9819. doi:10.1128/MCB.25.22.98069819.2005

Deregibus, M. C., Buttiglieri, S., Russo, S., Bussolati, B., and Camussi, G. (2003). CD40-dependent activation of phosphatidylinositol 3-kinase/Akt pathway mediates endothelial cell survival and in vitro angiogenesis. $J$. Biol. Chem. 278, 18008-18014. doi:10.1074/jbc.M300711200

Dykstra, M., Cherukuri, A., Sohn, H. W., Tzeng, S. J., and Pierce, S. K (2003). Location is everything: lipid rafts and immune cell signaling. Annu. Rev. Immunol. 21, 457-481. doi:10.1146/annurev.immunol.21. 120601.141021

Eggeling, C., Ringemann, C., Medda, R., Schwarzmann, G., Sandhoff, K., Polyakova, S., et al. (2009). Direct observation of the nanoscale dynamics of membrane lipids in a living cell. Nature 457, 1159-1162. doi:10.1038/nature07596

Faustman, D., and Davis, M. (2010). TNF receptor 2 pathway: drug target for autoimmune diseases. Nat. Rev. Drug Discov. 9, 482-493. doi:10.1038/nrd3030

Feng, X., Gaeta, M. L., Madge, L. A., Yang, J. H., Bradley, J. R., and Pober, J. S. (2001). Caveolin1 associates with TRAF2 to form a complex that is recruited to tumor necrosis factor receptors. J. Biol. Chem. 276, 8341-8349. doi:10.1074/jbc.M007116200

Finlay, D., and Cantrell, D. (2011). The coordination of T-cell function by serine/threonine kinases. Cold Spring Harb.
Perspect. Biol. 3, a002261. doi:10.1101/cshperspect.a002261

Fruman, D. A., and Bismuth, G. (2009). Fine tuning the immune response with PI3K. Immunol. Rev. 228, 253-272. doi:10.1111/j.1600065X.2008.00750.x

Gommerman, J. L., and Summers deLuca, L. (2011). LTbetaR and CD40: working together in dendritic cells to optimize immune responses. Immunol. Rev. 244, 85-98. doi:10.1111/j.1600065X.2011.01056.x

Graham, J. P., Arcipowski, K. M., and Bishop, G. A. (2010). Differential B-lymphocyte regulation by CD40 and its viral mimic, latent membrane protein 1. Immunol. Rev. 237, 226-248. doi:10.1111/j.1600065X.2010.00932.x

Gramaglia, I., Jember, A., Pippig, S. D., Weinberg, A. D., Killeen, N., and Croft, M. (2000). The OX40 costimulatory receptor determines the development of CD4 memory by regulating primary clonal expansion. J. Immunol. 165, 3043-3050.

Grell, M., Douni, E., Wajant, H., Lohden, M., Clauss, M., Maxeiner, B., et al. (1995). The transmembrane form of tumor necrosis factor is the prime activating ligand of the 80 $\mathrm{kDa}$ tumor necrosis factor receptor. Cell 83, 793-802. doi:10.1016/00928674(95)90192-2

Gupta, M., Dillon, S. R., Ziesmer, S. C., Feldman, A. L., Witzig, T. E., Ansell, S. M., et al. (2009). A proliferationinducing ligand mediates follicular lymphoma B-cell proliferation and cyclin D1 expression through phosphatidylinositol 3-kinase-regulated mammalian target of rapamycin activation. Blood 113, 5206-5216. doi:10.1182/blood-2008-09-179762

Ha, H., Kwak, H. B., Lee, S. K., Na, D. S., Rudd, C. E., Lee, Z. H., et al. (2003). Membrane rafts play a crucial role in receptor activator of nuclear factor kappaB signaling and osteoclast function. J. Biol. Chem. 278, 18573-18580. doi:10.1074/jbc.M212626200 
Hanna, A. N., Chan, E. Y., Xu, J., Stone, J. C., and Brindley, D. N. (1999). A novel pathway for tumor necrosis factor-alpha and ceramide signaling involving sequential activation of tyrosine kinase, p21(ras), and phosphatidylinositol 3-kinase. J. Biol. Chem. 274, 12722-12729. doi:10.1074/jbc.274.18.12722

Haswell, L. E., Glennie, M. J., and Al-Shamkhani, A. (2001). Analysis of the oligomeric requirement for signaling by CD40 using soluble multimeric forms of its ligand, CD154. Eur. J. Immunol. 31, 3094-3100. doi:10.1002/15214141(2001010)31:10<3094::AIDIMMU3094>3.0.CO;2-F

Hatzoglou, A., Roussel, J., Bourgeade, M. F., Rogier, E., Madry, C., Inoue, J., et al. (2000). TNF receptor family member BCMA (B cell maturation) associates with TNF receptorassociated factor (TRAF) 1, TRAF2, and TRAF3 and activates NF-kappa B, elk-1, c-Jun N-terminal kinase, and p38 mitogen-activated protein kinase. J. Immunol. 165, 1322-1330.

Haxhinasto, S., Mathis, D., and Benoist, C. (2008). The AKTmTOR axis regulates de novo differentiation of CD4+Foxp3+ cells. J. Exp. Med. 205, 565-574. doi:10.1084/jem.20071477

Hemingway, F., Kashima, T. G., Knowles, H. J., and Athanasou, N. A. (2013). Investigation of osteoclastogenic signalling of the RANKL substitute LIGHT. Exp. Mol. Pathol. 94, 380-385. doi:10.1016/j.yexmp.2013.01.003

Henley, T., Kovesdi, D., and Turner, M. (2008). B-cell responses to B-cell activation factor of the TNF family (BAFF) are impaired in the absence of PI3K delta. Eur. J. Immunol. 38, 3543-3548. doi:10.1002/eji.200838618

Hiraoka, E., Kawashima, S., Takahashi, T., Rikitake, Y., Kitamura, T., Ogawa, W., et al. (2001). TNF-alpha induces protein synthesis through PI3-kinase-Akt/PKB pathway in cardiac myocytes. Am. J. Physiol. Heart Circ. Physiol. 280, H1861-H1868.

Hosokawa, Y., Hosokawa, I., Ozaki, K., Nakae, H., and Matsuo, T. (2006). Proinflammatory effects of tumour necrosis factor-like weak inducer of apoptosis (TWEAK) on human gingival fibroblasts. Clin. Exp. Immunol. 146, 540-549. doi:10.1111/j.13652249.2006.03233. $\mathrm{x}$

Hosokawa, Y., Hosokawa, I., Shindo, S., Ozaki, K., Nakae, H., and Matsuo, T. (2012). Tumor necrosis factor-like weak inducer of apoptosis increases CC chemokine ligand 20 production in interleukin 1beta-stimulated human gingival fibroblasts. Hum. Immunol. 73, 470-473. doi:10.1016/j.humimm.2012.02. 021

Hostager, B. S., Catlett, I. M., and Bishop, G. A. (2000). Recruitment of CD40 and tumor necrosis factor receptor-associated factors 2 and 3 to membrane microdomains during CD40 signaling. J. Biol. Chem. 275, 15392-15398. doi:10.1074/jbc.M909520199

Huang, C. S., Zhou, J., Feng, A. K., Lynch, C. C., Klumperman, J., Dearmond, S. J., et al. (1999). Nerve growth factor signaling in caveolae-like domains at the plasma membrane. $J$. Biol. Chem. 274, 36707-36714. doi:10.1074/jbc.274.51.36707

Huang, Y. H., and Sauer, K. (2010). Lipid signaling in T-cell development and function. Cold Spring Harb. Perspect. Biol. 2, a002428. doi:10.1101/cshperspect.a002428

Ibanez, C. F., and Simi, A. (2012). p75 Neurotrophin receptor signaling in nervous system injury and degeneration: paradox and opportunity. Trends Neurosci. 35, 431-440. doi:10.1016/j.tins.2012.03.007

Ingold, K., Zumsteg, A., Tardivel, A., Huard, B., Steiner, Q. G., Cachero, T. G., et al. (2005). Identification of proteoglycans as the APRIL-specific binding partners. J. Exp. Med. 201, 1375-1383. doi:10.1084/jem.20042309

Ishii, N., Takahashi, T., Soroosh, P., and Sugamura, K. (2010). OX40-OX40 ligand interaction in T-cell-mediated immunity and immunopathology. Adv. Immunol. 105, 63-98. doi:10.1016/S00652776(10)05003-0

Ito, T., Wang, Y. H., Duramad, O., Hanabuchi, S., Perng, O. A., Gilliet, M., et al. (2006). OX40 ligand shuts down IL-10-producing regulatory $\mathrm{T}$ cells. Proc. Natl. Acad. Sci. U.S.A. 103, 13138-13143. doi:10.1073/pnas.0603107103

Jackson, T. R., Blader, I. J., HammondsOdie, L. P., Burga, C. R., Cooke, F., Hawkins, P. T., et al. (1996). Initiation and maintenance of NGF-stimulated neurite outgrowth requires activation of a phosphoinositide 3-kinase. J. Cell Sci. 109(Pt 2), 289-300.

Jang, I. K., Lee, Z. H., Kim, Y. J., Kim, S. H., and Kwon, B. S. (1998). Human 4-1BB (CD137) signals are mediated by TRAF2 and activate nuclear factor-kappa B. Biochem. Biophys. Res. Commun. 242, 613-620. doi:10.1006/bbrc. 1997.8016
Josefowicz, S. Z., Lu, L. F., and Rudensky, A. Y. (2012). Regulatory $\mathrm{T}$ cells: mechanisms of differentiation and function. Annu. Rev. Immunol. 30, 531-564. doi:10.1146/annurev.immunol.25.02 2106.141623

Kawamata, S., Hori, T., Imura, A., Takaori-Kondo, A., and Uchiyama, T. (1998). Activation of OX40 signal transduction pathways leads to tumor necrosis factor receptor-associated factor (TRAF) 2- and TRAF5mediated NF-kappaB activation. J. Biol. Chem. 273, 5808-5814. doi:10.1074/jbc.273.10.5808

Khursigara, G., Orlinick, J. R., and Chao, M. V. (1999). Association of the p75 neurotrophin receptor with TRAF6. J. Biol. Chem. 274, 2597-2600. doi:10.1074/jbc.274.5.2597

Kim, E. Y., Priatel, J. J., Teh, S. J., and Teh, H. S. (2006). TNF receptor type 2 (p75) functions as a costimulator for antigen-driven $\mathrm{T}$ cell responses in vivo. J. Immunol. 176, 1026-1035.

Kim, E. Y., and Teh, H. S. (2001). TNF type 2 receptor (p75) lowers the threshold of $\mathrm{T}$ cell activation. $J$. Immunol. 167, 6812-6820.

Kim, E. Y., and Teh, H. S. (2004). Critical role of TNF receptor type-2 (p75) as a costimulator for IL-2 induction and $\mathrm{T}$ cell survival: a functional link to CD28. J. Immunol. 173 , 4500-4509.

Kimberley, F. C., Van Bostelen, L., Cameron, K., Hardenberg, G., Marquart, J. A., Hahne, M., et al. (2009). The proteoglycan (heparan sulfate proteoglycan) binding domain of APRIL serves as a platform for ligand multimerization and crosslinking. FASEB J. 23, 1584-1595. doi:10.1096/fj.08-124669

Kumar, M., Makonchuk, D. Y., Li, H., Mittal, A., and Kumar, A. (2009). TNF-like weak inducer of apoptosis (TWEAK) activates proinflammatory signaling pathways and gene expression through the activation of TGF-beta-activated kinase 1. J. Immunol. 182, 2439-2448. doi:10.4049/jimmunol.0803357

Lasserre, R., Guo, X. J., Conchonaud, F. Hamon, Y., Hawchar, O., Bernard, A. M., et al. (2008). Raft nanodomains contribute to Akt/PKB plasma membrane recruitment and activation. Nat. Chem. Biol. 4, 538-547. doi:10.1038/nchembio. 103

Lee, H. W., Nam, K. O., Park, S. J., and Kwon, B. S. (2003). 4-1BB enhances $\mathrm{CD} 8+\mathrm{T}$ cell expansion by regulating cell cycle progression through changes in expression of cyclins D and E and cyclindependent kinase inhibitor p27kip1. Eur. J. Immunol. 33, 2133-2141. doi:10.1002/eji.200323996

Lee, H. W., Park, S. J., Choi, B. K., Kim, H. H., Nam, K. O., and Kwon, B. S. (2002). 4-1BB promotes the survival of CD8+ T lymphocytes by increasing expression of Bcl-xL and Bfl-1. J. Immunol. 169, 4882-4888.

Lee, S. H., Kim, E. J., Suk, K., Kim, I. S., and Lee, W. H. (2010). TL1A induces the expression of TGF-beta-inducible gene h3 (betaig-h3) through PKC, PI3K, and ERK in THP-1 cells. Cell. Immunol. 266, 61-66. doi:10.1016/j.cellimm.2010.08.013

Leibbrandt, A., and Penninger, J. M. (2008). RANK/RANKL: regulators of immune responses and bone physiology. Ann. N. Y. Acad. Sci. 1143, 123-150. doi:10.1196/annals.1443.016

Leonardi, A., Ellinger-Ziegelbauer, H., Franzoso, G., Brown, K., and Siebenlist, U. (2000). Physical and functional interaction of filamin (actinbinding protein-280) and tumor necrosis factor receptor-associated factor 2. J. Biol. Chem. 275, 271-278. doi:10.1074/jbc.275.1.271

Liu, Y., Xu, L., Opalka, N., Kappler, J., Shu, H. B., and Zhang, G. (2002). Crystal structure of sTALL-1 reveals a virus-like assembly of TNF family ligands. Cell 108, 383-394. doi:10.1016/S00928674(02)00631-1

Madireddi, S., Schabowsky, R. H., Srivastava, A. K., Sharma, R. K., Yolcu, E. S., and Shirwan, H. (2012). SA-4-1BBL costimulation inhibits conversion of conventional CD4+ $\mathrm{T}$ cells into CD4+ FoxP3+ $\mathrm{T}$ regulatory cells by production of IFN-gamma. PLoS ONE 7:e42459. doi:10.1371/journal.pone.0042459

Marchetti, L., Klein, M., Schlett, K., Pfizenmaier, K., and Eisel, U. L. (2004). Tumor necrosis factor (TNF)-mediated neuroprotection against glutamate-induced excitotoxicity is enhanced by $\mathrm{N}$-methyl-D-aspartate receptor activation. Essential role of a TNF receptor 2-mediated phosphatidylinositol 3-kinasedependent NF-kappa B pathway. J. Biol. Chem. 279, 32869-32881. doi:10.1074/jbc.M311766200

Marsters, S. A., Ayres, T. M., Skubatch, M., Gray, C. L., Rothe, M., and Ashkenazi, A. (1997). Herpesvirus entry mediator, a member of the tumor necrosis factor receptor (TNFR) family, interacts with members of the TNFR-associated factor 
family and activates the transcription factors NF-kappaB and AP-1. J. Biol. Chem. 272, 14029-14032. doi:10.1074/jbc.272.22.14029

Meylan, F., Richard, A. C., and Siegel, R. M. (2011). TL1A and DR3, a TNF family ligand-receptor pair that promotes lymphocyte costimulation, mucosal hyperplasia, and autoimmune inflammation. Immunol. Rev. 244, 188-196. doi:10.1111/j.1600065X.2011.01068.x

Moreaux, J., Legouffe, E., Jourdan, E., Quittet, P., Reme, T., Lugagne, C., et al. (2004). BAFF and APRIL protect myeloma cells from apoptosis induced by interleukin 6 deprivation and dexamethasone. Blood 103, 3148-3157. doi:10.1182/blood2003-06-1984

Muller, N., Wyzgol, A., Munkel, S., Pfizenmaier, K., and Wajant, H. (2008). Activity of soluble OX40 ligand is enhanced by oligomerization and cell surface immobilization. FEBS J. 275, 2296-2304. doi:10.1111/j.17424658.2008.06382.x

Nam, K. O., Kang, H., Shin, S. M., Cho, K. H., Kwon, B., Kwon, B. S., et al. (2005). Cross-linking of 4-1BB activates TCR-signaling pathways in CD8+ T lymphocytes. J. Immunol. 174, 1898-1905.

Novoyatleva, T., Diehl, F., Van Amerongen, M. J., Patra, C., Ferrazzi, F., Bellazzi, R., et al. (2010). TWEAK is a positive regulator of cardiomyocyte proliferation. Cardiovasc. Res. 85, 681-690. doi:10.1093/cvr/cvp360

Okkenhaug, K. (2013). Signaling by the phosphoinositide 3-kinase family in immune cells. Annu. Rev. Immunol. 31, 675-704. doi:10.1146/annurevimmunol-032712-095946

Osawa, Y., Banno, Y., Nagaki, M., Brenner, D. A., Naiki, T., Nozawa, Y., et al. (2001). TNFalpha-induced sphingosine 1-phosphate inhibits apoptosis through a phosphatidylinositol 3-kinase/Akt pathway in human hepatocytes. J. Immunol. 167, 173-180.

Otipoby, K. L., Sasaki, Y., SchmidtSupprian, M., Patke, A., Gareus, R., Pasparakis, M., et al. (2008). BAFF activates Akt and Erk through BAFF-R in an IKK1-dependent manner in primary mouse $B$ cells. Proc. Natl. Acad. Sci. U.S.A. 105, 12435-12438. doi:10.1073/pnas.08054 60105

Ozes, O. N., Mayo, L. D., Gustin, J. A., Pfeffer, S. R., Pfeffer, L. M., and Donner, D. B. (1999). NF-kappaB activation by tumour necrosis factor requires the Akt serine-threonine kinase. Nature 401, 82-85. doi:10.1038/43466

Pages, F., Ragueneau, M., Rottapel, R., Truneh, A., Nunes, J., Imbert, J., et al. (1994). Binding of phosphatidylinositol-3-OH kinase to $\mathrm{CD} 28$ is required for T-cell signalling. Nature 369, 327-329. doi:10.1038/369327a0

Park, Y. C., Burkitt, V., Villa, A. R., Tong, L., and Wu, H. (1999). Structural basis for self-association and receptor recognition of human TRAF2. Nature 398, 533-538. doi:10.1038/19110

Pastorino, J. G., Tafani, M., and Farber, J. L. (1999). Tumor necrosis factor induces phosphorylation and translocation of BAD through a phosphatidylinositide3-OH kinase-dependent pathway. J. Biol. Chem. 274, 19411-19416. doi:10.1074/jbc.274.27.19411

Patke, A., Mecklenbrauker, I., Erdjument-Bromage, H., Tempst, P., and Tarakhovsky, A. (2006). BAFF controls B cell metabolic fitness through a PKC betaand Akt-dependent mechanism. J. Exp. Med. 203, 2551-2562. doi:10.1084/jem.20060990

Pike, L. J., and Casey, L. (1996). Localization and turnover of phosphatidylinositol 4,5bisphosphate in caveolin-enriched membrane domains. J. Biol. Chem. 271, 26453-26456. doi:10.1074/jbc.271.43.26453

Porquet, N., Poirier, A., Houle, F., Pin, A. L., Gout, S., Tremblay, P. L., et al. (2011). Survival advantages conferred to colon cancer cells by Eselectin-induced activation of the PI3K-NFkappaB survival axis downstream of Death receptor-3. BMC Cancer 11:285. doi:10.1186/14712407-11-285

Pullen, S. S., Miller, H. G., Everdeen, D. S., Dang, T. T., Crute, J. J., and Kehry, M. R. (1998). CD40-tumor necrosis factor receptor-associated factor (TRAF) interactions: regulation of CD40 signaling through multiple TRAF binding sites and TRAF hetero-oligomerization. Biochemistry 37, 11836-11845. doi:10.1021/bi981067q

Reddy, S. A., Huang, J. H., and Liao, W.S. (2000). Phosphatidylinositol 3kinase as a mediator of TNF-induced NF-kappa B activation. J. Immunol. 164, 1355-1363.

Ren, C. L., Morio, T., Fu, S. M., and Geha, R. S. (1994). Signal transduction via CD40 involves activation of lyn kinase and phosphatidylinositol-3-kinase, and phosphorylation of phospholipase
C gamma 2. J. Exp. Med. 179, 673-680. doi:10.1084/jem.179.2.673

Rickert, R. C., Jellusova, J., and Miletic, A. V. (2011). Signaling by the tumor necrosis factor receptor superfamily in B-cell biology and disease. Immunol. Rev. 244, 115-133. doi:10.1111/j.1600065X.2011.01067.x

Rogers, P. R., Song, J., Gramaglia, I., Killeen, N., and Croft, M. (2001). OX40 promotes Bcl$\mathrm{xL}$ and $\mathrm{Bcl}-2$ expression and is essential for long-term survival of CD4 $\mathrm{T}$ cells. Immunity 15, 445-455. doi:10.1016/S1074-7613 (01)00191-1

Rothe, M., Wong, S. C., Henzel, W. J., and Goeddel, D. V. (1994). A novel family of putative signal transducers associated with the cytoplasmic domain of the $75 \mathrm{kDa}$ tumor necrosis factor receptor. Cell 78, 681-692. doi:10.1016/0092-8674(94)90532-0

Sanz, A. B., Sanchez-Nino, M. D., Izquierdo, M. C., Jakubowski, A., Justo, P., Blanco-Colio, L. M., et al. (2009). Tweak induces proliferation in renal tubular epithelium: a role in uninephrectomy induced renal hyperplasia. J. Cell. Mol. Med. 13, 3329-3342. doi:10.1111/j.15824934.2009.00766.x

Sauer, S., Bruno, L., Hertweck, A., Finlay, D., Leleu, M., Spivakov, M., et al. (2008). T cell receptor signaling controls Foxp3 expression via PI3K, Akt, and mTOR. Proc. Natl. Acad. Sci. U.S.A. 105, 7797-7802. doi:10.1073/pnas.0800928105

Schreiber, T. H., Wolf, D., Tsai, M. S., Chirinos, J., Deyev, V. V., Gonzalez, L., et al. (2010). Therapeutic Treg expansion in mice by TNFRSF 25 prevents allergic lung inflammation. J. Clin. Invest. 120, 3629-3640. doi:10.1172/JCI42933

Shu, H. B., and Johnson, H. (2000). B cell maturation protein is a receptor for the tumor necrosis factor family member TALL-1. Proc. Natl. Acad. Sci. U.S.A. 97, 9156-9161. doi:10.1073/pnas.160213497

Snell, L. M., Lin, G. H., McPherson, A. J., Moraes, T. J., and Watts, T. H. (2011). T-cell intrinsic effects of GITR and 4-1BB during viral infection and cancer immunotherapy. Immunol. Rev. 244, 197-217. doi:10.1111/j.1600065X.2011.01063.X

So, T., Choi, H., and Croft, M. (2011a). OX40 complexes with phosphoinositide 3-kinase and protein kinase $\mathrm{B}$ (PKB) to augment TCR-dependent PKB signaling. J. Immunol. 186, 3547-3555. doi:10.4049/jimmunol.1003156
So, T., Soroosh, P., Eun, S. Y., Altman, A., and Croft, M. (2011b). Antigen-independent signalosome of CARMA1, PKCtheta, and TNF receptor-associated factor 2 (TRAF2) determines NF-kappaB signaling in $\mathrm{T}$ cells. Proc. Natl. Acad. Sci. U.S.A. 108, 2903-2908. doi:10.1073/pnas.1008765108

So, T., and Croft, M. (2007). Cutting edge: OX40 inhibits TGF-beta- and antigen-driven conversion of naive CD4 T cells into CD25+Foxp3+ T cells. J. Immunol. 179, 1427-1430.

So, T., Lee, S. W., and Croft, M. (2006). Tumor necrosis factor/tumor necrosis factor receptor family members that positively regulate immunity. Int. J. Hematol. 83, 1-11. doi:10.1532/IJH97.05120

So, T., Lee, S. W., and Croft, M. (2008). Immune regulation and control of regulatory $\mathrm{T}$ cells by OX40 and 4-1BB. Cytokine Growth Factor Rev. 19, 253-262. doi:10.1016/j.cytogfr.2008.04.003

Soltoff, S. P., Rabin, S. L., Cantley, L. C., and Kaplan, D. R. (1992). Nerve growth factor promotes the activation of phosphatidylinositol 3kinase and its association with the trk tyrosine kinase. J. Biol. Chem. 267, 17472-17477.

Song, J., Salek-Ardakani, S., Rogers, P. R., Cheng, M., Van Parijs, L., and Croft, M. (2004). The costimulation-regulated duration of PKB activation controls $\mathrm{T}$ cell longevity. Nat. Immunol. 5, 150-158. doi:10.1038/ni1030

Song, J., So, T., Cheng, M., Tang, X., and Croft, M. (2005). Sustained survivin expression from OX40 costimulatory signals drives $\mathrm{T}$ cell clonal expansion. Immunity 22, 621-631. doi:10.1016/j.immuni.2005.03.012

Soroosh, P., Doherty, T. A., So, T., Mehta, A. K., Khorram, N., Norris, P. S., et al. (2011). Herpesvirus entry mediator (TNFRSF14) regulates the persistence of T helper memory cell populations. J. Exp. Med. 208, 797-809. doi:10.1084/jem.20101562

Starck, L., Scholz, C., Dorken, B., and Daniel, P. T. (2005). Costimulation by CD137/4-1BB inhibits $\mathrm{T}$ cell apoptosis and induces $\mathrm{Bcl}-\mathrm{xL}$ and cFLIP(short) via phosphatidylinositol 3-kinase and AKT/protein kinase B. Eur. J. Immunol. 35, 1257-1266. doi:10.1002/eji.200425686

Steinberg, M. W., Cheung, T. C., and Ware, C. F. (2011). The signaling networks of the herpesvirus entry mediator (TNFRSF14) in immune regulation. Immunol. Rev. 244, 169-187. doi:10.1111/j.1600065X.2011.01064.x 
Stone, G. W., Barzee, S., Snarsky, V., Kee, K., Spina, C. A., Yu, X. F., et al. (2006). Multimeric soluble CD40 ligand and GITR ligand as adjuvants for human immunodeficiency virus DNA vaccines. J. Virol. 80, 1762-1772. doi:10.1128/ JVI.80.4.1762-1772.2006

Takano, R., Hisahara, S., Namikawa, K., Kiyama, H., Okano, H., and Miura, M. (2000). Nerve growth factor protects oligodendrocytes from tumor necrosis factor-alpha-induced injury through Akt-mediated signaling mechanisms. J. Biol. Chem. 275, 16360-16365. doi:10.1074/jbc.M910419199

Vaillant, A. R., Mazzoni, I., Tudan, C., Boudreau, M., Kaplan, D. R., and Miller, F. D. (1999). Depolarization and neurotrophins converge on the phosphatidylinositol 3-kinase-Akt pathway to synergistically regulate neuronal survival. J. Cell Biol. 146, 955-966. doi:10.1083/jcb.146.5.955

Vidalain, P. O., Azocar, O., ServetDelprat, C., Rabourdin-Combe, C., Gerlier, D., and Manie, S. (2000). CD40 signaling in human dendritic cells is initiated within membrane rafts. EMBO J. 19, 3304-3313. doi:10.1093/emboj/19.13.3304

Vilar, M., Charalampopoulos, I., Kenchappa, R. S., Simi, A., Karaca, E., Reversi, A., et al. (2009). Activation of the p75 neurotrophin receptor through conformational rearrangement of disulphide-linked receptor dimers. Neuron 62, 72-83. doi:10.1016/j.neuron.2009.02.020

Vinay, D. S., and Kwon, B. S. (2012). Immunotherapy of cancer with 4-1BB. Mol. Cancer Ther. 11, 1062-1070. doi:10.1158/15357163.MCT-11-0677

Viola, A., and Gupta, N. (2007). Tether and trap: regulation of membraneraft dynamics by actin-binding proteins. Nat. Rev. Immunol. 7, 889-896. doi:10.1038/nri2193

Vu, M. D., Xiao, X., Gao, W., Degauque, N., Chen, M., Kroemer, A., et al. (2007). OX40 costimulation turns off Foxp3+ Tregs. Blood 110, 2501-2510. doi:10.1182/blood2007-01-070748

Ware, C. F., and Sedy, J. R. (2011). TNF Superfamily Networks: bidirectional and interference pathways of the herpesvirus entry mediator (TNFSF14). Curr.
Opin. Immunol. 23, 627-631. doi:10.1016/j.coi.2011.08.008

Watts, T. H. (2005). TNF/TNFR family members in costimulation of $\mathrm{T}$ cell responses. Annu. Rev. Immunol. 23, 23-68. doi:10.1146/annurev.immunol.23. 021704.115839

Wei, C. Y., Chou, Y. H., Ho, F. M., Hsieh, S. L., and Lin, W. W. (2006). Signaling pathways of LIGHT induced macrophage migration and vascular smooth muscle cell proliferation. J. Cell. Physiol. 209, 735-743. doi:10.1002/jcp.20742

Wong, B. R., Besser, D., Kim, N., Arron, J. R., Vologodskaia, M., Hanafusa, H., et al. (1999). TRANCE, a TNF family member, activates Akt/PKB through a signaling complex involving TRAF6 and c-Src. Mol. Cell 4, 1041-1049. doi:10.1016/S10972765(00)80232-4

Wong, B. R., Josien, R., Lee, S. Y., Vologodskaia, M., Steinman, R. M., and Choi, Y. (1998). The TRAF family of signal transducers mediates NF-kappaB activation by the TRANCE receptor. J. Biol. Chem. 273, 28355-28359. doi:10.1074/jbc.273.43.28355

Woodland, R. T., Fox, C. J., Schmidt, M. R., Hammerman, P. S., Opferman, J. T., Korsmeyer, S. J., et al. (2008). Multiple signaling pathways promote B lymphocyte stimulator dependent B-cell growth and survival. Blood 111, 750-760. doi:10.1182/blood-2007-03-077222

Wyzgol, A., Muller, N., Fick, A., Munkel, S., Grigoleit, G. U., Pfizenmaier, K., et al. (2009). Trimer stabilization, oligomerization, and antibody-mediated cell surface immobilization improve the activity of soluble trimers of CD27L, CD40L, 41BBL, and glucocorticoidinduced TNF receptor ligand. J. Immunol. 183, 1851-1861. doi:10.4049/jimmunol.0802597

Xia, X. Z., Treanor, J., Senaldi, G., Khare, S. D., Boone, T., Kelley, M., et al. (2000). TACI is a TRAF-interacting receptor for TALL-1, a tumor necrosis factor family member involved in B cell regulation. J. Exp. Med. 192, 137-143. doi:10.1084/jem.192.1.137

Xing, L., Venegas, A. M., Chen, A. Garrett-Beal, L., Boyce, B. F., Varmus, H. E., et al. (2001). Genetic evidence for a role for Src family kinases in TNF family receptor signaling and cell survival. Genes Dev. 15, 241-253. doi:10.1101/gad.840301

Xu, L. G., and Shu, H. B. (2002). TNFRassociated factor-3 is associated with BAFF-R and negatively regulates BAFF-R-mediated NF-kappa B activation and IL-10 production. J. Immunol. 169, 6883-6889.

Yang, W. L., Wang, J., Chan, C. H., Lee, S. W., Campos, A. D., Lamothe, B., et al. (2009). The E3 ligase TRAF6 regulates Akt ubiquitination and activation. Science 325, 1134-1138. doi:10.1126/science.1175065

Yao, R., and Cooper, G. M. (1995). Requirement for phosphatidylinositol-3 kinase in the prevention of apoptosis by nerve growth factor. Science 267, 2003-2006. doi:10.1126/science.7701324

Ye, X., Mehlen, P., Rabizadeh, S., Vanarsdale, T., Zhang, H., Shin, H., et al. (1999). TRAF family proteins interact with the common neurotrophin receptor and modulate apoptosis induction. $J$. Biol. Chem. 274, 30202-30208. doi:10.1074/jbc.274.42.30202

Yu, Q., Kovacs, C., Yue, F. Y., and Ostrowski, M. A. (2004). The role of the p38 mitogen-activated protein kinase, extracellular signal-regulated kinase, and phosphoinositide-3-OH kinase signal transduction pathways in CD40 ligand-induced dendritic cell activation and expansion of virus-specific CD8+ T cell memory responses. J. Immunol. 172, 6047-6056.

Zhang, G. (2004). Tumor necrosis factor family ligand-receptor binding. Curr. Opin. Struct. Biol. 14, 154-160. doi:10.1016/j.sbi.2004.03.003

Zhang, H. G., Wang, Y., Xie, J. F., Liang, X., Liu, D., Yang, P., et al. (2001). Regulation of tumor necrosis factor alpha-mediated apoptosis of rheumatoid arthritis synovial fibroblasts by the protein kinase Akt. Arthritis Rheum. 44 1555-1567. doi:10.1002/15290131(200107)44:7<1555::AIDART279>3.0.CO;2-M

Zhang, Q., Cui, F., Fang, L., Hong, J., Zheng, B., and Zhang, J. Z. (2013). TNF-alpha impairs differentiation and function of TGF-beta-induced Treg cells in autoimmune diseases through Akt and Smad3 signaling pathway. J. Mol. Cell Biol. 5, 85-98. doi:10.1093/jmcb/mjs063
Zhang, R., Xu, Y., Ekman, N., Wu, Z., Wu, J., Alitalo, K., et al. (2003a). Etk/Bmx transactivates vascular endothelial growth factor 2 and recruits phosphatidylinositol 3kinase to mediate the tumor necrosis factor-induced angiogenic pathway. J. Biol. Chem. 278, 51267-51276. doi:10.1074/jbc.M310678200

Zhang, Z., Jimi, E., and Bothwell, A. L. (2003b). Receptor activator of NFkappa B ligand stimulates recruitment of SHP-1 to the complex containing TNFR-associated factor 6 that regulates osteoclastogenesis. $J$. Immunol. 171, 3620-3626.

Zhou, Z., Song, X., Berezov, A., Zhang, G., Li, Y., Zhang, H., et al. (2008). Human glucocorticoid-induced TNF receptor ligand regulates its signaling activity through multiple oligomerization states. Proc. Natl. Acad. Sci. U.S.A. 105, 5465-5470. doi:10.1073/pnas.0711350105

Zonca, M., Mancheno-Corvo, P., Delarosa, O., Manes, S., Buscher, D., Lombardo, E., et al. (2012). APRIL and BAFF proteins increase proliferation of human adipose-derived stem cells through activation of Erk1/2 MAP kinase. Tissue Eng. Part A 18, 852-859. doi:10.1089/ten.tea.2011.0316

Conflict of Interest Statement: The authors declare that the research was conducted in the absence of any commercial or financial relationships that could be construed as a potential conflict of interest.

Received: 04 April 2013; paper pending published: 06 May 2013; accepted: 25 May 2013; published online: 07 June 2013.

Citation: So T and Croft M (2013) Regulation of PI-3-kinase and Akt signaling in Tlymphocytes and other cells by TNFR family molecules. Front. Immunol. 4:139. doi: 10.3389/fimmu.2013.00139

This article was submitted to Frontiers in $T$ Cell Biology, a specialty of Frontiers in Immunology.

Copyright (c) 2013 So and Croft. This is an open-access article distributed under the terms of the Creative Commons Attribution License, which permits use, distribution and reproduction in other forums, provided the original authors and source are credited and subject to any copyright notices concerning any third-party graphics etc. 